\title{
Progeroid syndrome patients with ZMPSTE24 deficiency could benefit when treated with rapamycin and dimethylsulfoxide
}

\author{
Baris Akinci, ${ }^{1}$ Shireesha Sankella, ${ }^{1}$ Christopher Gilpin, ${ }^{2}$ Keiichi Ozono, ${ }^{3}$ \\ Abhimanyu Garg, ${ }^{1}$ and Anil K. Agarwal ${ }^{1}$ \\ ${ }^{1}$ Division of Nutrition and Metabolic Diseases, Center for Human Nutrition, Department of Internal Medicine, \\ University of Texas Southwestern Medical Center, Dallas, Texas 75390, USA; ${ }^{2}$ Molecular and Cellular Imaging, \\ Department of Cell Biology, University of Texas Southwestern Medical Center, Dallas, Texas 75390, USA; \\ ${ }^{3}$ Department of Pediatrics, Osaka University Graduate School of Medicine, Osaka 565-0871, Japan
}

Corresponding author: Anil. Agarwal@utsouthwestern.edu

(C) 2017 Akinci et al. This article is distributed under the terms of the Creative Commons Attribution-NonCommercial License, which permits reuse and redistribution, except for commercial purposes, provided that the original author and source are credited.

Ontology terms: severe postnatal growth retardation

Published by Cold Spring Harbor Laboratory Press

doi: $10.1101 /$ mcs.a001339
Abstract Patients with progeroid syndromes such as mandibuloacral dysplasia, type B (MADB) and restrictive dermopathy (RD) harbor mutations in zinc metalloproteinase (ZMPSTE24), an enzyme essential for posttranslational proteolysis of prelamin A to form mature lamin A. Dermal fibroblasts from these patients show increased nuclear dysmorphology and reduced proliferation; however, the efficacy of various pharmacological agents in reversing these cellular phenotypes remains unknown. In this study, fibroblasts from MADB patients exhibited marked nuclear abnormalities and reduced proliferation that improved upon treatment with rapamycin and dimethylsulfoxide but not with other agents, including farnesyl transferase inhibitors. Surprisingly, fibroblasts from an RD patient with a homozygous null mutation in ZMPSTE24, resulting in exclusive accumulation of prelamin A with no lamin A on immunoblotting of cellular lysate, exhibited few nuclear abnormalities and near-normal cellular proliferation. An unbiased proteomic analysis of the cellular lysate from RD fibroblasts revealed a lack of processing of vimentin, a cytoskeletal protein. Interestingly, the assembly of the vimentin microfibrils in MADB fibroblasts improved with rapamycin and dimethylsulfoxide. We conclude that rapamycin and dimethylsulfoxide are beneficial for improving nuclear morphology and cell proliferation of MADB fibroblasts. Data from a single RD patient's fibroblasts also suggest that prelamin $A$ accumulation by itself might not be detrimental and requires additional alterations at the cellular level to manifest the phenotype.

[Supplemental material is available for this article.]

\section{INTRODUCTION}

Loss-of-function mutations in lamin A/C (LMNA) and zinc metalloproteinase (ZMPSTE24) genes are found in various progeroid disorders including the autosomal dominant Hutchinson-Gilford progeria syndrome (Merideth et al. 2008) (HGPS, OMIM 176670), the autosomal recessive mandibuloacral dysplasia (Young et al. 1971; Novelli et al. 2002) (MAD, OMIM 248370 and 608612), and restrictive dermopathy (Dale et al. 1987; Holbrook et al. 1987; Navarro et al. 2004) (RD, OMIM 275210). LMNA encodes the nuclear lamina protein lamin A, and by alternate splicing in exon 10 encodes lamin C. Lamin A is formed after posttranslational processing of prelamin $A$, but lamin $C$ does not undergo 
COLD SPRING HARBOR Molecular Case Studies
Treating MAD and RD patients with rapamycin and DMSO

further processing. ZMPSTE24 encodes a microsomal protease that cleaves the prenylated prelamin A containing the CAAX (Cysteine-Aliphatic-Aliphatic-Any amino acid) motif at its carboxyl end (Agarwal et al. 2003; Michaelis and Barrowman 2012). The cysteine residue in the cysteine, serine, isoleucine, and methionine (CSIM) motif of prelamin A undergoes farnesylation by the farnesyl transferase enzyme followed by removal of SIM tripeptide by ZMPSTE24. This partially processed farnesylated prelamin A is methylated and then further cleaved 15 residues upstream by ZMPSTE24 to produce a mature lamin A.

Patients with RD harbor null mutations in ZMPSTE24 on both alleles, have the most severe phenotype, and die within a few hours to a few weeks of birth. Patients with HGPS have a median survival of 12-14 yr and a de novo heterozygous missense LMNA mutation that induces an abnormal donor splice site in exon 11, resulting in accumulation of truncated farnesylated prelamin A, called progerin, because of deletion of the second proteolytic site for ZMPSTE24. Patients with MAD have a variable survival rate depending upon the severity. Patients with MAD, type $A$ (MADA) with LMNA mutations have a milder phenotype as compared to those with type $B$ (MADB) harboring ZMPSTE24 mutations. In contrast to patients with $R D$, most patients with MADB are compound heterozygotes with a null mutation on one allele and a missense mutation resulting in a partially active ZMPSTE24 mutant on the other allele. Therefore, the severity of the disease phenotype might result from the residual ZMPSTE24 enzymatic activity. In fact, recent in vitro protease activities of several ZMPSTE24 mutants corroborate this observation (Barrowman et al. 2012b). Those mutants with no measurable protease activity are associated with RD and those that are partially active result in MAD (Barrowman et al. 2012b). Several new mutations in ZMPSTE24 have recently been reported in MADB or RD (Navarro et al. 2014; Wang et al. 2016). A heterozygous ZMPSTE24 mutation is also shown to be associated with severe metabolic syndrome, abnormal fat accumulation, and dilated cardiomyopathy (Galant et al. 2016).

Primary dermal fibroblasts from most patients with these progeroid disorders exhibit characteristic nuclear blebbing and a reduced cellular proliferation. The precise mechanisms by which mutations in LMNA or ZMPSTE24 cause this nuclear dysmorphology remain unclear. Several pharmacological agents, such as farnesyl transferase inhibitors, statins, bisphosphonates, and rapamycin have been reported to rescue the nuclear abnormalities seen in the fibroblasts from HGPS patients; these observations were the basis for clinical trials in HGPS patients. However, whether a similar approach will work in patients with MADB or RD who have partial or complete ZMPSTE24 deficiency, resulting in accumulation of farnesylated prelamin A, is not clear. Therefore, we investigated the efficacy of various pharmacological agents in improving the abnormal nuclear phenotype in skin fibroblasts from four patients with MADB and one patient with RD. Additionally, we used these fibroblasts in an unbiased proteomic approach seeking additional substrate(s) for ZMPSTE24, which might provide clues to the severity of the phenotype seen in patients with RD.

\section{RESULTS}

\section{Clinical Presentation and Family History}

The clinical features of the patients used in this study have been described elsewhere and are presented in Supplemental Table S1. Affected subjects from pedigree MAD3300 of Japanese origin (Miyoshi et al. 2008) and MAD4700 of European origin (Ahmad et al. 2010) had compound heterozygous mutations in ZMPSTE24 in which one allele carried a null mutation and the other allele carried a missense mutation. The affected RD patient of Mexican origin had a homozygous null mutation in ZMPSTE24 (Ahmad et al. 2012). The RD patient died a few days after birth, whereas all the MADB patients are alive. 
COLD SPRING HARBOR Molecular Case Studies
Treating MAD and RD patients with rapamycin and DMSO

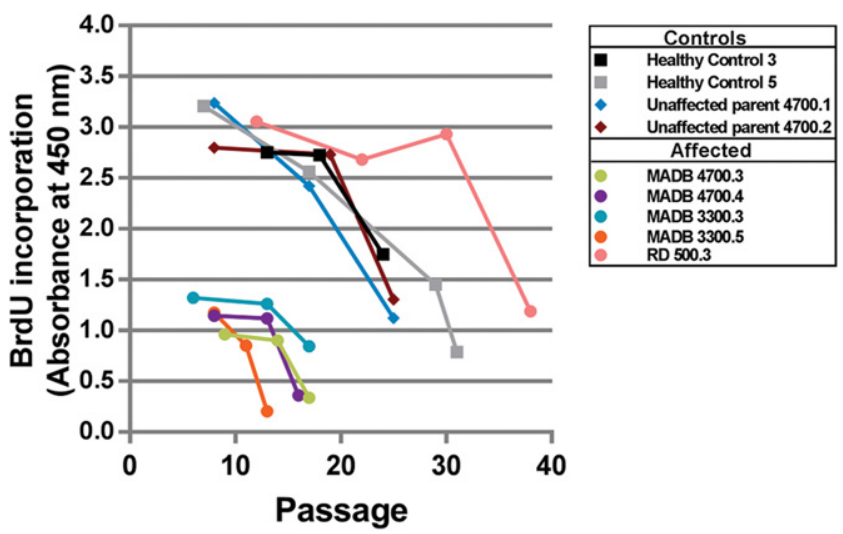

Figure 1. Cellular proliferation measurement of fibroblasts from patients with mandibuloacral dysplasia (MAD) and restrictive dermopathy (RD). Fibroblasts were passaged continually, and at the cell passages some cells were assayed for the incorporation of bromodeoxyuridine (BrdU) in the proliferating cells. The proliferation was observed in the unaffected control and in the unaffected parents (4700.1 and 4700.2) of MAD pedigree, whereas affected subjects $(4700.3,4700.4,3300.3$, and 3300.5) showed reduced incorporation of BrdU with increasing passages. The fibroblasts from the patient with RD (500.3) appeared to have a similar proliferation rate as the control fibroblasts used in this study.

\section{Functional Analyses}

\section{Differences in Senescence in RD and MADB Patient Dermal Fibroblasts}

The cellular proliferation of the cultured fibroblasts from all the subjects of pedigree MAD4700, patients from pedigree MAD3300 (MAD3300.3 and 3300.5), and the RD500.3 patient were tested by incorporation of $\mathrm{BrdU}$ in the proliferating cells at various passages of cell growth. Fibroblasts from unaffected controls and those of unaffected parents (MAD4700.1 and MAD4700.2) showed a similar senescence profile (Fig. 1) with reduced proliferation starting around passages 17-19. However, fibroblasts from affected subjects MAD4700.3, 4700.4, 3300.3 , and 3300.5 had significantly reduced incorporation of BrdU even at early passages (passages 6-9) and stopped proliferating by passages 13-16. Despite the fact that affected fibroblasts from RD500.3 had only prelamin A, these fibroblasts showed no sign of reduced proliferation at passage 30 , but they started to slow down around passage 38 . Prior studies have noticed abnormal nuclear morphology in fibroblasts obtained from patients with RD (Navarro et al. 2004, 2005). However, these studies did not quantify the cellular proliferation.

\section{Detection of Prelamin A, Lamin A, and Lamin C in Fibroblasts from MAD and RD Patients} Loss of functional ZMPSTE24 will result in defective processing of prelamin A. Displayed in Figure $2 \mathrm{~A}$ are the immunoblots for prelamin $\mathrm{A}$ and lamins $\mathrm{A} / \mathrm{C}$. We probed the protein blots with antibody that recognizes the amino terminus of the lamin $A / C$ proteins. Compared to the unaffected controls and unaffected parents of MADB patients where we could detect both lamins $A$ and $C$, the affected children MAD4700.3 and MAD4700.4 showed the presence of prelamin $A$ as well as lamins $A$ and $C$. Prelamin $A$ was also detected in the fibroblasts of affected child MAD3300.3. Although we detected the presence of both prelamin $A$ and lamin A in MADB patients, the RD500.3 patient showed only the presence of prelamin A (Fig. 2A) with no detectable level of lamin A (Fig. 2A). The presence of prelamin A was detectable in fibroblasts from RD500.3 even at late passage 32 (Supplemental Fig. S1A). We did not observe any significant changes in the expression of lamin $C$ in these patients. Upon quantification of prelamin A compared to lamin C, the ratios of unaffected/related controls were similar, whereas affected subjects have significantly increased expressions of prelamin $\mathrm{A}$ 


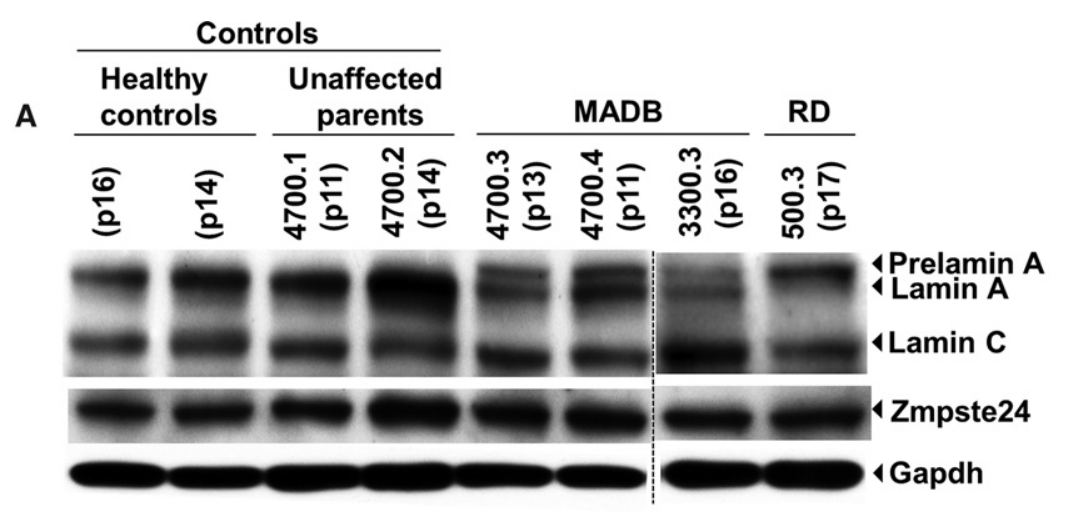

B

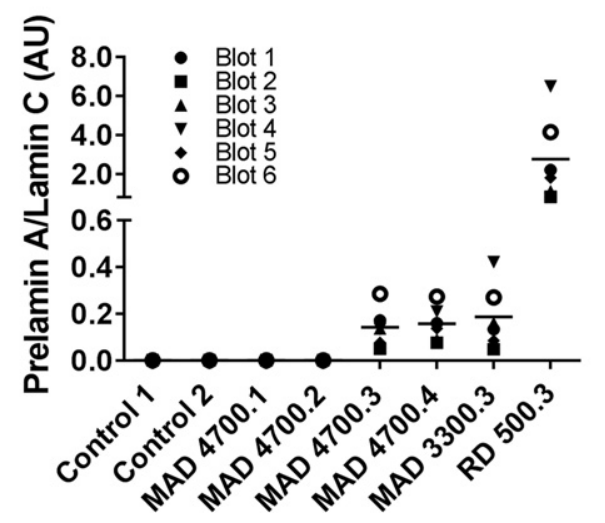

C

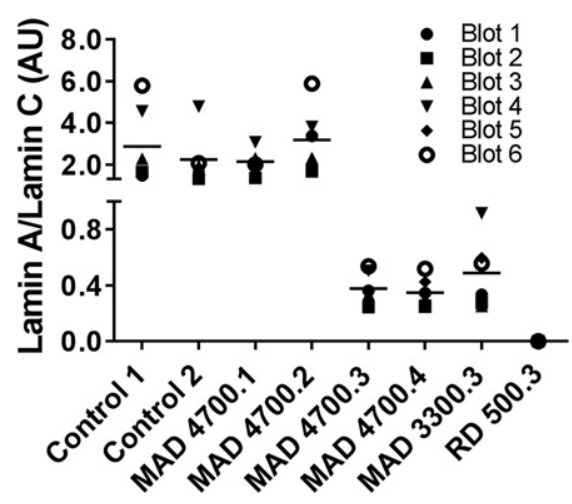

Figure 2. Immunoblot analysis of prelamin $A$ and mature lamin $A$ and $C$ in the fibroblasts from mandibuloacral dysplasia, type $B(M A D B)$ and restrictive dermopathy $(R D)$ patients. $(A)$ The presence of prelamin $A$ in the fibroblasts from the affected patients MAD4700.3 and 4700.4 at earlier passages 11-13 and MAD3300.3. Note in RD500.3 only prelamin A could be detected. Shown also are the immunoblots for the ZMPSTE24 protein. $(B, C)$ The quantification of lamins in these samples as estimated by Image $\mathrm{J}$. The ratio of prelamin $A$ to lamin $C$ remains similar in unaffected controls and in parents of affected patients, MAD4700.1 and 4700.2. This ratio tends to increase in affected patients and is several-fold higher in RD500.3 (B). The ratio of lamin $\mathrm{A} /$ lamin $\mathrm{C}$ is also altered in affected subjects. Comparison for the ratio between lamin $\mathrm{A}$ and lamin $\mathrm{C}$ between these groups was also statistically significant $(C)$. Symbols represent individual quantifications of blots presented in $B$ and $C ; n=6 ; P<0.001$; (AU) arbitrary units.

(Fig. 2B). However, this ratio was the highest for RD500.3. The presence of increased prelamin A also disturbs the ratio of lamin A to lamin C (Fig. 2C). We also tested the effect of dimethyl sulfoxide (DMSO) $(1 \%)$ or rapamycin $(1 \mu \mathrm{M})$ on the expression of prelamin $A$ in MADB4700.3 cells by performing an immunoblot analysis. We observed no change in prelamin A or lamin A/C levels in the presence of DMSO or rapamycin in the controls (Supplemental Fig. S1B). In MADB4700.3, we observed that lamin A/C levels were increased in the presence of rapamycin but remained unchanged when treated with DMSO. Prelamin A remained unchanged in the presence of DMSO or rapamycin (Supplemental Fig. S1B).

Treatment with DMSO and Rapamycin Improves Abnormal Nuclear Morphology in Fibroblasts from Patients

Several reports have shown that accumulation of progerin in the fibroblasts from HGPS patients leads to abnormal nuclear morphology, which could be rescued by treatment with 
COLD SPRING HARBOR Molecular Case Studies
Treating MAD and RD patients with rapamycin and DMSO farnesyltransferase, CAAX box, alpha (FNTA, also known as FTase) inhibitor (Fong et al. 2006; Yang et al. 2008), protein geranylgeranyltransferase type 1 subunit beta (PGGT1B, also known as GGTase) inhibitor (Chang et al. 2012), statins, zoledronic acid (Varela et al. 2008), $\mathrm{N}$-acetylcysteine (NAC) (Richards et al. 2011), suberoylanilide hydroxamic acid (SAHA) (Marks and Breslow 2007), insulin-like growth factor 1 (IGF1) (Sadeghi-Nejad and Demmer 2007; Marino et al. 2010), or rapamycin (Cao et al. 2011; Ramos et al. 2012). However, treating the MADB and RD fibroblasts with these agents did not improve the nuclear morphology (Fig. 3), except upon treatment with rapamycin prepared in DMSO (Fig. 4A), where we observed a significant improvement in the nuclear blebbing or nuclear envelope invagination. More intriguing was our observation that a similar improvement in nuclear morphology was noted even when cells were treated with DMSO alone. DMSO toxicity was tested in fibroblasts by incubating with $0.3,1,3$, or $10 \%$ DMSO for $14 \mathrm{~d}$ (Supplemental Fig. S2). Cells were examined every alternate day for cell death, which includes cell rounding and detachment from the dish. DMSO was not toxic at $0.3 \%$ and $1 \%$ but showed progressive toxicity with increased DMSO concentrations. At 3\% we observed $30 \%$ death at day 14 . However, at $10 \%$ DMSO most of the cells died within $24 \mathrm{~h}$ (99\%). To further identify whether the nuclear morphology improvements were due to the DMSO treatment and not rapamycin, we then incubated the cells with rapamycin dissolved in ethanol. As displayed in Figure 4B, we could see improvement in nuclear morphology in fibroblasts treated with rapamycin that was not evident in fibroblasts treated with ethanol alone. These data, although confirming the previous observations of the beneficial effect of rapamycin in Hutchinson-Gilford progeria syndrome (HGPS) fibroblasts (Cao et al. 2011), also revealed the role of DMSO itself in improving the nuclear morphology of these cells.

\section{Electron Microscopy Images of Fibroblasts Treated with DMSO Showed Improvement in Nuclear Morphology}

We followed the light microscopy observations of the beneficial effects of DMSO by examining the nucleus of these fibroblasts at a higher resolution. We observed a significant number of small vesicle-like structures near the nuclear envelope in the fibroblasts from affected patients MAD4700.3 and MAD4700.4 (Fig. 5) compared to unaffected control fibroblasts. Upon treatment with DMSO alone, these vesicle-like structures were significantly reduced. These vesicle-like structures failed to improve upon treatment with the FNTA inhibitor FTI277. These observations suggest a beneficial role of DMSO in improving the nuclear morphology or nucleoplasmic-cytoplasmic communication, which is important for proper cellular growth and function.

\section{Improvement of Nuclear Morphology Is Not Due to the Activation of MTOR Pathway in MAD4700.3 and RD500.3}

Rapamycin inhibits the activation of MTOR, which is a serine/theronine kinase belonging to the AGC family of kinases (cAMP-dependent, cGMP-dependent, and PKC) (Pearce et al. 2010). There are two MTORs, MTORC1 and MTORC2, depending on the presence of raptor and rictor components in these complexes, respectively (Zoncu et al. 2011). When the fibroblasts from affected patients were cultured in the presence of rapamycin or DMSO, we did not observe any significant changes in the levels of either total MTOR or MTORC2 (Supplemental Fig. S3). We did not notice any change in the levels of total AKT or phosphorylated AKT (pAKT), which are phosphorylated by MTORC2. Further, no changes in the MTORC2 phosphorylation level were noted with either treatment. The MTORC1 level was slightly decreased in DMSO and rapamycin-treated fibroblasts, but one of its downstream target proteins, ribosomal protein S6 kinase B1 (RPS6KB1, also known as S6K) or its 


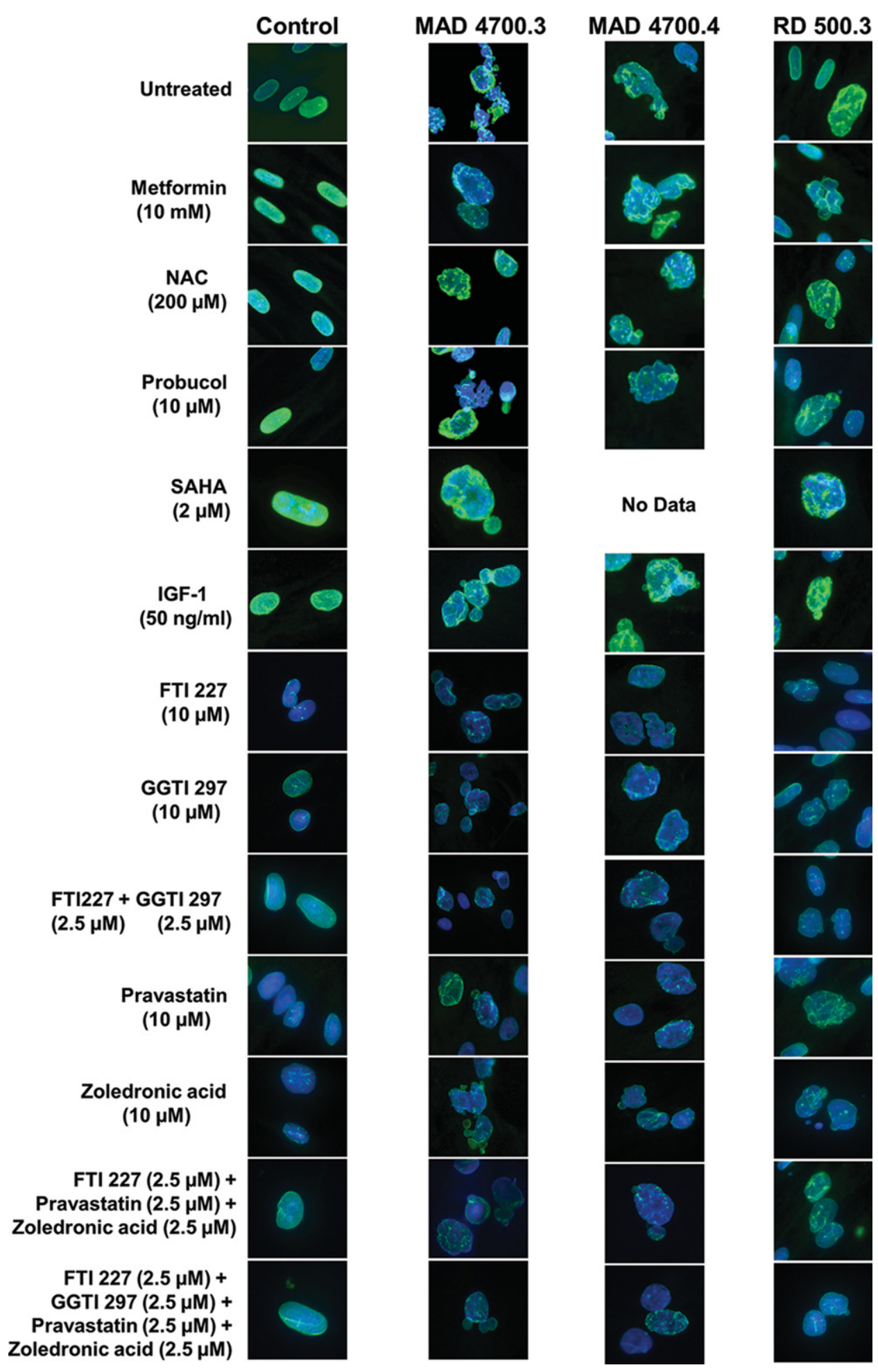

Figure 3. Nuclear morphology of dermal fibroblasts from healthy control, mandibuloacral dysplasia, type B (MADB) patients, MAD4700.3 and MAD4700.4 and restrictive dermopathy patient RD500.3, in response to various treatments. Shown are the representative nuclear images for each treatment. Approximately $25-50 \mathrm{nu}-$ clei for each treatment were observed. Details of the treatments are described in Methods. 

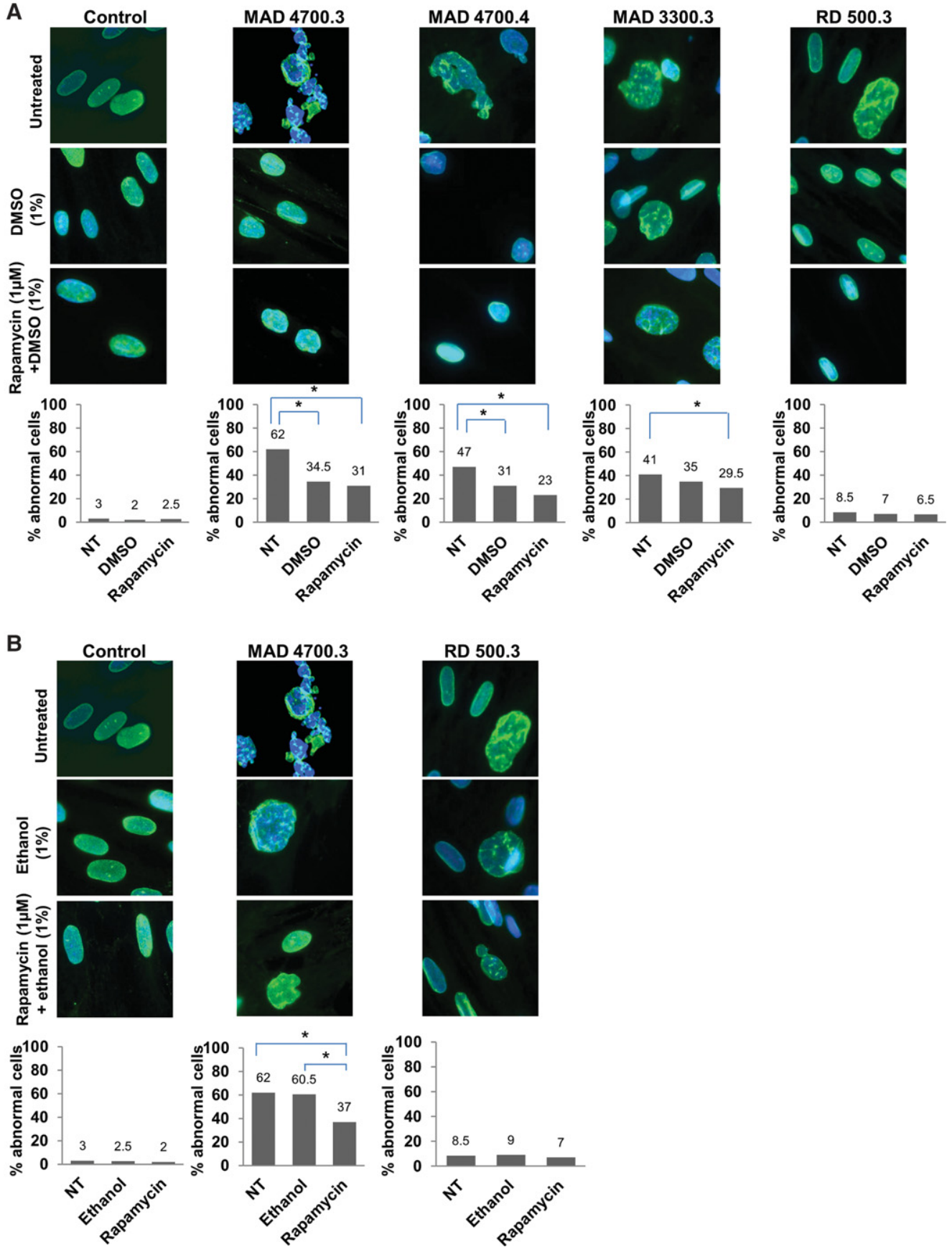

Figure 4. Nuclear morphology of dermal fibroblasts from affected mandibuloacral dysplasia (MAD) and restrictive dermopathy (RD) patients in response to rapamycin dissolved in dimethyl sulfoxide (DMSO) and DMSO-alone treatment. (A) The indirect immunofluorescence images of nuclei stained for lamin $A$ and lamin C proteins with and without DMSO (1\%) and rapamycin $(1 \mu \mathrm{M})$ treatment for $14 \mathrm{~d}$. In contrast to control fibroblasts, patients with MAD $(4700.3,4700.4$, and 3300.3) show significant instances of abnormal nuclear morphology that improved upon treatment with DMSO and rapamycin. We observed very few fibroblasts with abnormal nuclear morphology from the patient with RD. (B) Similar improvements in nuclear morphology of the MAD4700.3 patient were observed when fibroblasts were treated with rapamycin prepared in ethanol. Again, no changes were noted with RD500.3. Approximately 200 nuclei were observed for each treatment and an asterisk $\left({ }^{*}\right)$ denotes statistical significance of $P<0.001$ between various groups. (NT) Untreated. 

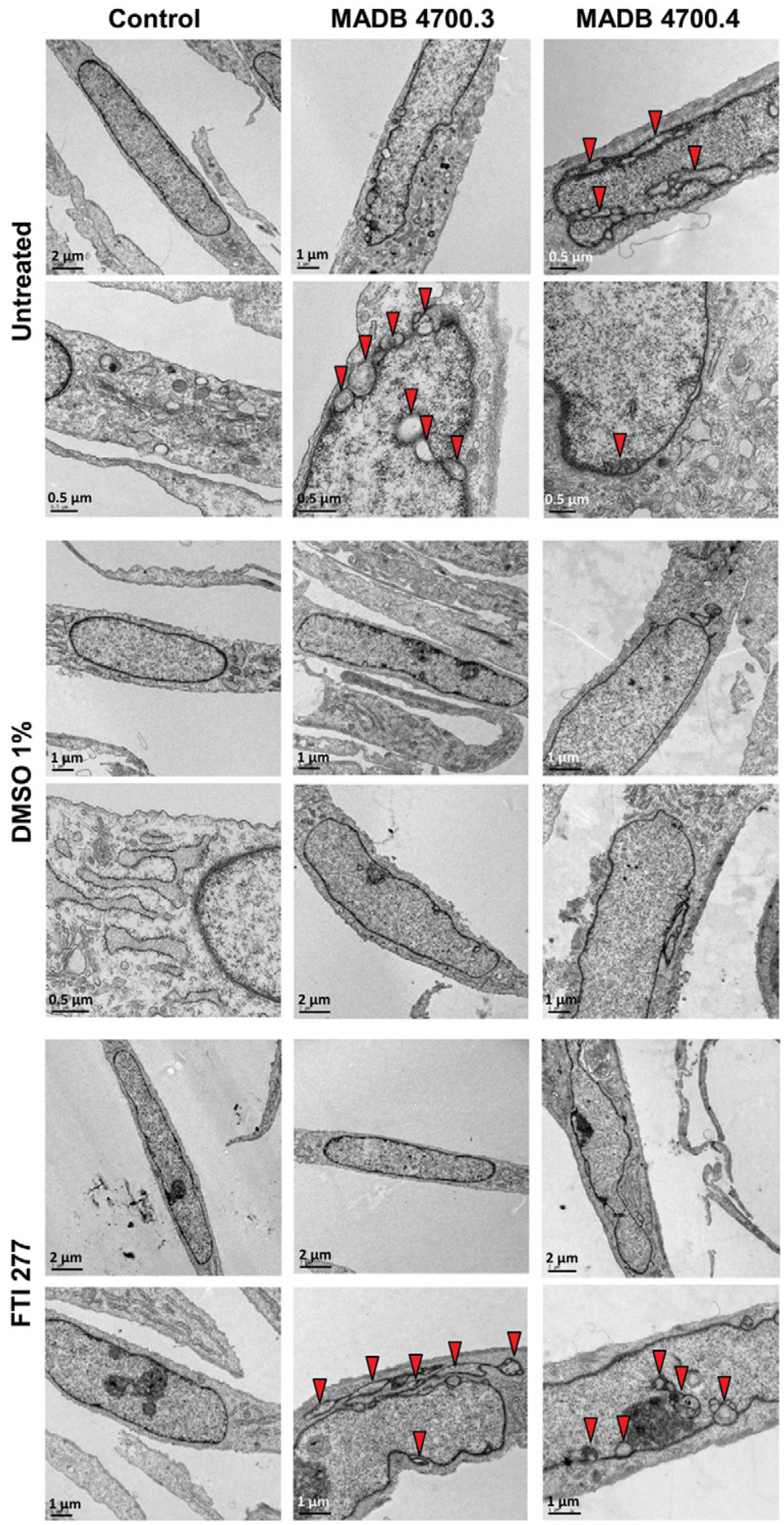

Figure 5. Electron micrograph images of nuclei in fibroblasts obtained from patients with mandibuloacral dysplasia (MAD) after treatment with dimethyl sulfoxide (DMSO) and a farnesyltransferase inhibitor, FTI-277. Marked with red triangles are the "vesicle-like structures," which could represent nuclear invaginations not seen in the unaffected nuclei. Such "vesicle-like structures" are not seen in fibroblasts treated with DMSO. FTI-277 treatment failed to inhibit these features in the patients with MAD. Scale bars are shown in the images. All images were within $0.5-2 \mu \mathrm{m}$. 
phosphorylated form (pRPS6KB1), remained unaffected. We included DMSO as a treatment in this assay although it is not known if DMSO affects the MTOR signaling pathway.

\section{Expression of CDKN2A ( $p 16^{\text {Ink4a }}$ ) Protein in MADB 4700.3 Fibroblasts}

Cyclin-dependent kinase inhibitor 2A (CDKN2A) promotes cell-cycle arrest and is used as a marker for senescence (Campisi and d'Adda di Fagagna 2007). Increased expression of CDKN2A has been shown to contribute to cellular aging (Campisi 2001). A schematic for the function of CDKN2A is shown in Supplemental Figure S4. CDKN2A is a cyclin-dependent kinase inhibitor that binds to and inactivates cyclin-dependent kinase 4/6 (CDK4/6), which in turn inhibits hyperphosphorylation of RB transcriptional corepressor 1 (RB1, also known as retinoblastoma protein [pRB]), which then precludes the dissociation of E2F transcription factor (E2F) from RB1 and thus arrests cell division and cellular growth. We examined the expression of CDKN2A in the control and MADB4700.3 fibroblasts (Supplemental Fig. S4B). Immunoblots for CDKN2A protein expression show a slight increase in the expression of CDKN2A in fibroblasts from MADB4700.3 compared to control fibroblasts. We did not attempt quantification for this western blot because of limited data and therefore quantification might not be reliable. We interpret this result with caution because unavailability of MADB4700.3 fibroblasts precludes us from performing additional experiments (Supplemental Fig. S4B).

\section{Alterations in Protein Levels in Affected Patient Fibroblasts}

ZMPSTE24 is an ortholog of yeast Ste24, which in yeast produces the mating factor-the afactor (Michaelis and Barrowman 2012). The processing of the yeast a-factor is very similar to the processing of prelamin A in mammals, as shown in Figure 6A,B (Michaelis and Barrowman 2012). In fact, the expression of human ZMPSTE24 in yeast lacking Ste24/Rce1 proteins efficiently processes and produces the a-factor (used for the halo assay) (Agarwal et al. 2003). Recent mutational studies using human prelamin $A$ revealed that the number of residues from the prenylated cysteine is critical for the processing of prelamin A (Barrowman et al. 2012a). When the residues were increased from 15 to either 24 or 33 amino acids, ZMPSTE24 progressively failed to cleave prelamin A (Barrowman et al. 2012a). However, the same ZMPSTE24 can cleave yeast pre-a-factor protein between residues 7 and 8 in the amino terminus of the protein, which is 26 residues away from the prenylated cysteine residue. ZMPSTE24 lacks the specificity for the peptide bond it cleaves. In prelamin A, the cleavage occurs between residues tyrosine ${ }^{646}$ and leucine ${ }^{647}$ and, in yeast pre-a-factor, proteolysis occurs between amino acids threonine ${ }^{7}$ and alanine ${ }^{8}$. This lack of amino acid specificity as well as the distance from the prenylated cysteine, as suggested from the recent experiment, raises the possibility that additional substrates of ZMPSTE24 in mammals are yet to be discovered. Although no additional substrate for mammalian ZMPSTE24 has been found, its complementary function in producing mature yeast a-factor would suggest otherwise.

We analyzed the total protein from cultured fibroblasts obtained from patients MAD4700.4, MAD3300.3, and RD500.3. As displayed in Figure 6C,D, when the total proteins from the affected subject MAD4700.4 were compared to unaffected controls, several protein spots were revealed that were found to be either up- or down-regulated (Supplemental Fig. S5; Supplemental Table S2). As mentioned above, our rationale in identifying the protein spots was that the protein should change in size (molecular weight, MW) and in the isoelectric focusing point ( $\mathrm{pl}$ ) because of a change in the ratio of the electrical charge over the MW of the protein. We initially identified protein spots $32,33,37$, and 48 and protein spots $61,75,80$, and 82. Shown in Figure $6 C, D$ are also the fold changes between various affected groups. Protein spots 32, 33, 37, and 48 were identified as prelamin A. Prelamin A protein spots 32,33 , and 37 are of similar molecular weight but with a different pl. This could represent 
A

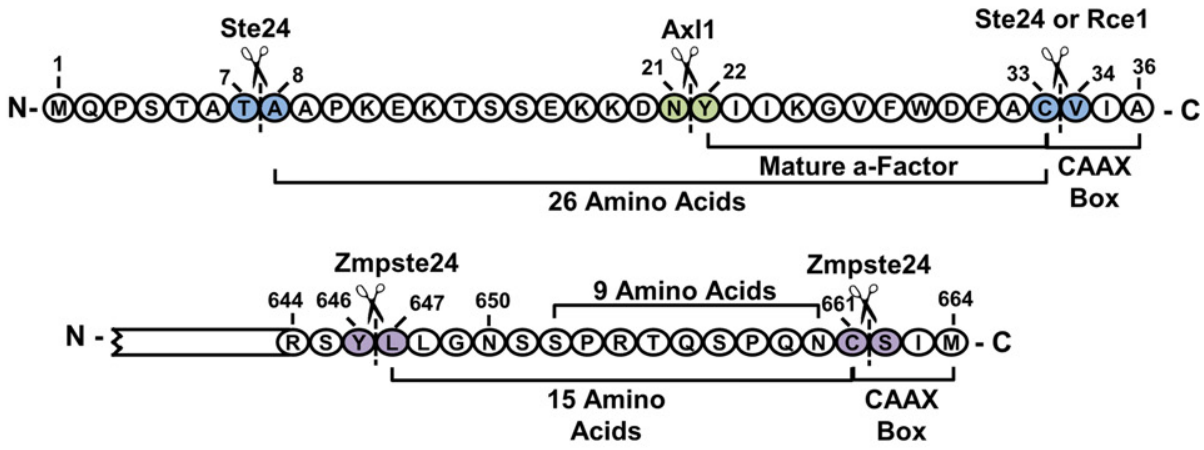

C

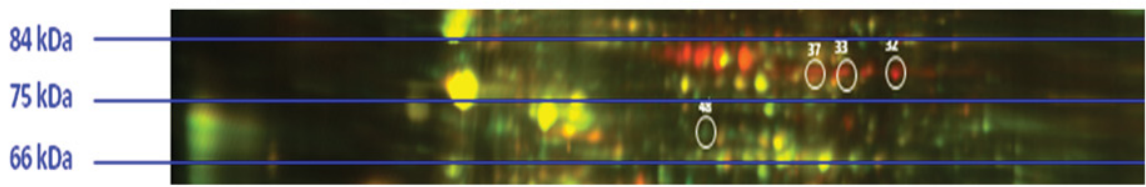

\begin{tabular}{|c|c|c|c|c|c|c|c|}
\hline $\begin{array}{c}\text { Protein ID/ } \\
\text { Spot }\end{array}$ & $\begin{array}{c}\mathbf{4 7 0 0 . 3 /} \\
\mathbf{C 3}\end{array}$ & $\begin{array}{c}\mathbf{4 7 0 0 . 4 /} \\
\mathbf{C 5}\end{array}$ & $\begin{array}{c}\mathbf{3 3 0 0 . 3 /} \\
\mathbf{4 7 0 0 . 1}\end{array}$ & $\begin{array}{c}\mathbf{5 0 0 . 3 /} \\
\mathbf{4 7 0 0 . 2}\end{array}$ & $\begin{array}{c}\text { Affected/ } \\
\text { Controls }\end{array}$ & $\begin{array}{c}\mathbf{( 4 7 0 0 . 3 + 4} / \mathbf{4} \\
\mathbf{( 4 7 0 0 . 1 + 2})\end{array}$ & $\begin{array}{c}\mathbf{4 7 0 0 . 4} \\
\mathbf{4 7 0 0 . 3}\end{array}$ \\
\hline $\begin{array}{c}\text { Prelamin-A/C/ } \\
\text { Spot 32 }\end{array}$ & 8.2 & 5.9 & 2.6 & 3.1 & 4.0 & 2.9 & 1.6 \\
\hline $\begin{array}{c}\text { Prelamin-A/C/ } \\
\text { Spot 33* }\end{array}$ & 3.2 & & 2.4 & & 2.8 & 2.2 & \\
\hline $\begin{array}{c}\text { Prelamin-A/C/ } \\
\text { Spot 37* }\end{array}$ & 1.2 & 4.2 & -1.1 & -1.1 & 1.5 & 1.5 & 1.8 \\
\hline $\begin{array}{c}\text { Prelamin-A/C/ } \\
\text { Spot 48* }\end{array}$ & -2.3 & -1.3 & 1.1 & 1.2 & -1.2 & 1.0 & 1.6 \\
\hline
\end{tabular}

D

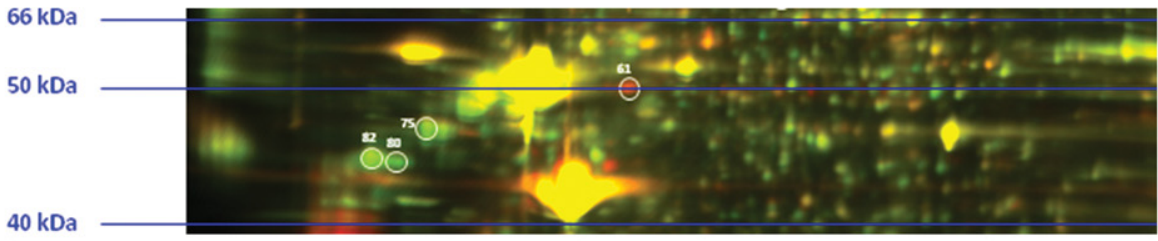

\begin{tabular}{|c|c|c|c|c|c|c|c|}
\hline $\begin{array}{c}\text { Protein ID/ } \\
\text { Spot }\end{array}$ & $\begin{array}{c}\begin{array}{c}4700.3 / \\
\mathrm{C} 3\end{array} \\
\end{array}$ & $\begin{array}{c}\begin{array}{c}4700.4 / \\
\mathrm{C} 5\end{array} \\
\end{array}$ & $\begin{array}{l}3300.31 \\
4700.1 \\
\end{array}$ & $\begin{array}{r}500.31 \\
4700.2 \\
\end{array}$ & \begin{tabular}{|l|} 
Affected/ \\
Controls \\
\end{tabular} & $\begin{array}{l}(4700.3+4) / \\
(4700.1+2)\end{array}$ & $\begin{array}{r}4700.4 / \\
4700.3 \\
\end{array}$ \\
\hline $\begin{array}{l}\text { Vimentin/ } \\
\text { Spot } 61\end{array}$ & 2.8 & 6.8 & -2.1 & 9.0 & 2.9 & 2.0 & 3.6 \\
\hline $\begin{array}{l}\text { Vimentin/ } \\
\text { Spot } 75^{*}\end{array}$ & -3.2 & -1.7 & & & -2.5 & & -1.2 \\
\hline $\begin{array}{l}\text { Vimentin/ } \\
\text { Spot } 80^{*}\end{array}$ & -6.0 & -2.2 & & & -4.3 & & -1.2 \\
\hline $\begin{array}{l}\text { Vimentin/ } \\
\text { Spot } 82^{*}\end{array}$ & & & 1.9 & & & 1.1 & \\
\hline
\end{tabular}

Figure 6. Schematic of yeast proprotein a-factor, human prelamin A, and total fibroblast proteins analyzed by two-dimensional-fluorescence difference gel electrophoresis (2D-DIGE). (A) The various amino acids and the peptide bonds cleaved by yeast CAAX prenyl protease/CAAX prenyl protease 2 (Ste24/Rce1) and putative protease (Ax|1). The generation of mature yeast a-factor is marked. (B) The partial carboxyl-terminal amino acids for human prelamin A and the proteolytic sites for zinc metalloprotease (ZMPSTE24). The CAAX motif is marked where $C$ is cysteine, AA denotes any two aliphatic residues, and $X$ is any amino acid. The amino acids are numbered from the amino terminus. For more details see the review by Michaelis and Barrowman (2012). (C) The prelamin A protein spots as identified by mass spectrometry detection. Also shown are the fold changes between various combinations of affected and unaffected subjects as well as within the MAD4700 pedigree. Only protein spot 48 showed a decreased molecular weight (MW) in most samples, which could represent lamin A or lamin C, and the several-fold increase in protein spots 32, 33, and 37 could represent prelamin A. These protein spots may represent other posttranslational modifications including lamin phosphorylation, as discussed in the text. (D) The protein identified as vimentin. Only protein spot 61 showed increased expression under various group comparisons, but protein spots 75, 80, and 82 also identified as vimentin were decreased and are of lower MW. 
a small-molecule posttranslational change. Lamins $\mathrm{A}$ and $\mathrm{C}$ have been shown to be phosphorylated by cyclin-dependent kinase 2 (CDK2) (Heald and McKeon 1990; Peter et al. 1990) or protein kinase C (PRKC, also known as PKC) (Thompson and Fields 1996; Collas 1999). Protein spots $61,75,80$, and 82 were identified as vimentin. Vimentin is a cytoskeleton protein, and it is possible that prelamin A accumulation might also affect this cytoskeletal protein.

\section{Cellular Architecture of Vimentin in MAD4700.3 and RD500.3 Fibroblasts upon Rapamycin and DMSO Treatment}

Although several proteins were identified in our proteomic analyses of ZMPSTE24-deficient fibroblasts, we first analyzed vimentin in these fibroblasts by immunostaining, because vimentin is a cytoskeleton protein and lamin A/C (including prelamin A) is a nuclear lamina protein. It is possible that a cytoplasmic-nuclear interaction might exist and provide additional cellular links for the progression of the disease. Unlike the lamin A/C staining, fibroblasts treated with DMSO alone or with rapamycin showed condensation of the vimentin fibrils (Fig. 7). This feature was prominent in the case of MAD4700.3. RD500.3 fibroblasts did not show significant abnormality in vimentin assembly. In MAD4700.3, vimentin fibers became well organized upon treatment with DMSO or rapamycin prepared in DMSO. However, the effect of pharmacological agents DMSO and rapamycin could not be appreciated in the RD500.3 fibroblasts.

\section{Expression of Vimentin in the Patients' Fibroblasts}

Next, we analyzed the presence of vimentin protein by western blot analysis. As shown in Figure 8A, we observed the presence of a faster migrating protein fragment on SDSPAGE (VIM II) compared to the slower migrating protein band VIM I. However, in fibroblasts from RD500.3 that show the presence of only prelamin A, no VIM II protein band was observed. The control or unaffected parents MAD4700.1 and MAD4700.2 had more VIM II protein than the affected MAD4700.3, MAD4700.4, and MAD3300.3 patients. When serial dilutions of total cellular lysates were analyzed from unaffected patients and RD500.3 (Fig. 8B), the presence of VIM II was quantitatively less in RD500.3 compared to control cellular lysate (Fig. 8C,D). This observation suggests that ZMPSTE24 mostly likely cleaves the vimentin protein in fibroblasts (Fig. 8E), which merits further confirmation.

\section{Cleavage of Vimentin in HeLa and RD500.3 Cells Is Not Dependent on ZMPSTE24}

We followed these observations by further expressing human vimentin tagged with Flag and V5 epitopes in HeLa cells where ZMPSTE24 is functional and in RD500.3 fibroblasts where ZMPSTE24 is genetically inactive (Fig. 8F). The expression of double-tagged vimentin should reveal the cleavage site when probed with amino terminus Flag or carboxyl terminus V5 epitope antibodies, respectively. However, such experiments did detect the fast migrating VIM II in both RD500.3 and HeLa cells (Fig. 8G,H). This observation failed to support the role of ZMPSTE24 in processing vimentin, suggesting that additional protease(s) might be responsible for proteolytic cleavage of vimentin.

\section{DISCUSSION}

We made several important observations in this study. We noticed that when the dermal fibroblasts from patients with MADB were treated with rapamycin dissolved in DMSO or ethanol, the nuclear morphology improved significantly. However, we also noted similar improvements in the nuclear morphology in the fibroblasts of MADB patients when treated with DMSO alone. The effect of DMSO was confirmed upon examining the cells with 

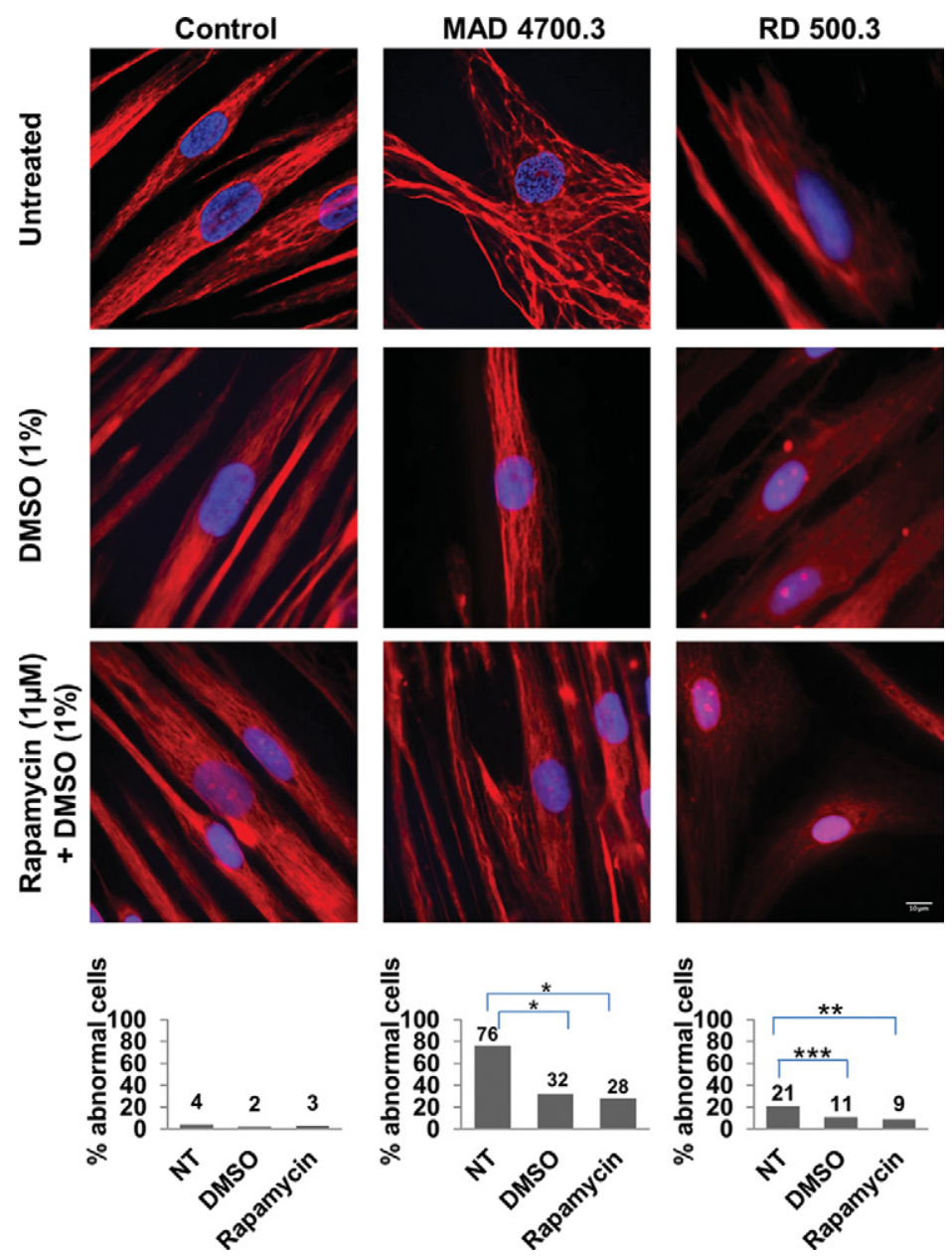

Figure 7. Indirect immunofluorescence images of fibroblasts treated with dimethyl sulfoxide (DMSO) or rapamycin and stained for vimentin. The fibroblasts from MAD4700.3 had irregular vimentin cytoskeletal architecture compared to the unaffected control subject. This abnormal vimentin cytoskeletal architecture improved dramatically and significantly upon DMSO and rapamycin treatments. Similar observations were made in restrictive dermopathy RD500.3 fibroblasts. Red false coloring represents vimentin, and blue represents DAPI (4',6-diamidino-2-phenylindole, dihydrochloride). All images were obtained under similar microscopic conditions; scale bar, $10 \mu \mathrm{m} ;\left(^{*}\right) P<0.001,\left({ }^{* *}\right) P=0.001$, (***) $P=0.009$. (NT) Untreated.

electron microscopy. Because DMSO is an antibacterial/antioxidant (Marks and Breslow 2007), we incubated cells with other antioxidants like SAHA and NAC but did not find any improvement in nuclear morphology as noted with DMSO. Thus, the effect of DMSO seems to be specific to the cells used in our study or it is specific to MADB patients.

Recently, the role of DMSO in improving the directed differentiation of pluripotent stem cells was reported (Chetty et al. 2013). In these pluripotent stem cells, DMSO increased the proportion of cells in the G1 phase of the cell cycle, which is mediated by the increased presence of hypophosphorylated RB1 (Chetty et al. 2013). DMSO also has antioxidative properties (Ali 2001), removing the harmful reactive oxygen species from the damaged tissues and cells. Two recent reports further suggest a role of antioxidants that might alleviate the aging phenotype in this syndrome (Hanzen et al. 2016; Kubben et al. 2016). Therefore, a further detailed investigation will be required to determine the molecular mechanism as to how DMSO improves the cellular morphology in our MADB patients. DMSO has been shown 
A

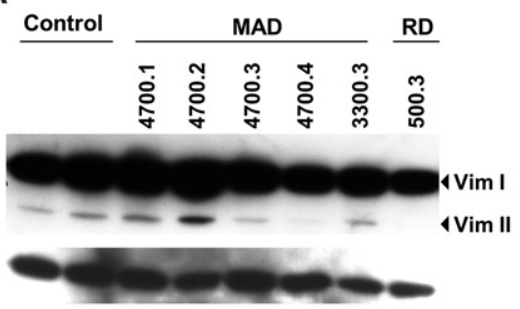

C

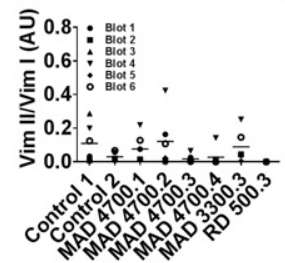

D

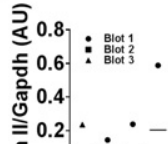

$0.2 . \cdots$

$50.0 \div \div \div+\div$

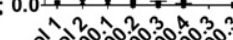

0

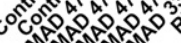

B
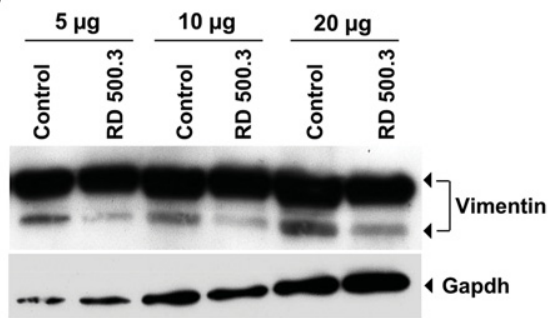

$\mathbf{E}$

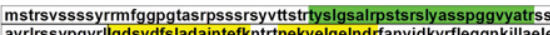
Iqsfrqdvdnaslarldlerkveslqeeiaflkk|heeeiqelqaqiqeqhvqidvdvskpdltaal dvrqqyesvaaknlqeaeewykskfadlseaanrnndalrqakqesteyrrqvqsitcevdali gtneslerqmremeenfaveaanyqdtigrlqdeignmkeemarhlreyqdllnvkmaldiei

F

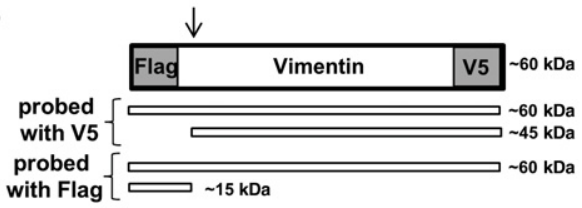

G

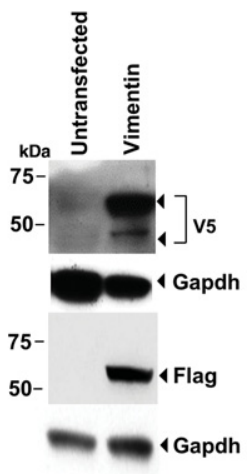

H

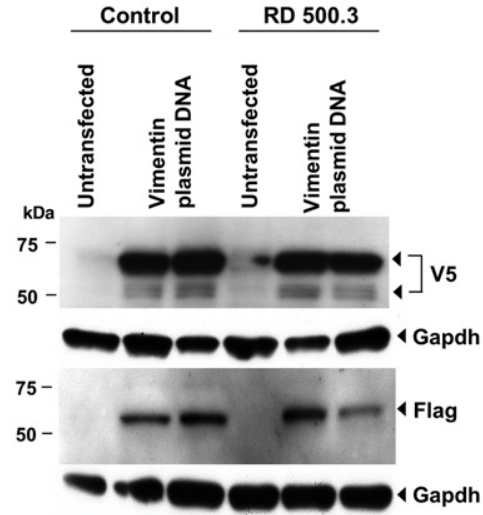

Figure 8. Immunoblot analysis of endogenous vimentin in the fibroblasts from MAD4700 pedigree, affected patients from MAD3300.3 and RD500.3, and exogenous expression of Flag-hVimentin-V5 tagged mammalian construct in HeLa cells and in RD500.3 fibroblasts. (A) Total cell lysate resolved on sodium dodecyl sulfatepolyacrylamide gel electrophoresis (SDS-PAGE) and probed with vimentin antibody showed vimentin (VIM I) and an additional faster migrating band, VIM II. VIM II was not detected in MAD4700.4 and RD500.3. (B) Upon protein titration from RD500.3, the level of VIM II was consistently less than that of the unaffected control. $(C, D)$ Quantification of VIM I and VIM II. The ratio changes in RD500.3 in favor of more VIM II. Only representative blots are shown. Symbols represent individual quantifications of blots presented in $A$ and $B$. The loading control protein GAPDH was determined for each blot. The ratios for VIM I/VIM II between various groups are all statistically significant. $P<0.01$; $(A U)$ arbitrary units. $(E)$ Amino acid sequence of human vimentin. The sequences highlighted in yellow were consistently detected on mass spectroscopy analysis. The boxed sequence was not detected in three out of four protein spots, whereas that in green was detected only once, suggesting proteolytic cleavage in this region of the vimentin. (F) Schematic of vimentin construct showing the Flag and V5 epitopes in the amino and carboxy terminus of the protein, respectively. $(G)$ Immunoblot of tagged vimentin expressed in HeLa cells that correctly process the prelamin A. Probing with V5 antibody detects a faster migrating band similar to RD500.3 fibroblasts probed with vimentin antibody $(A, B)$, indicating the amino terminus cleavage of the vimentin protein. However, when the same protein blot is stripped and reprobed with Flag antibody, only one protein band was detected; the expected smaller protein band was not detected. $(H) A$ similar observation was made when the tagged vimentin was expressed in RD500.3 fibroblasts, which carry the nonfunctional ZMPSTE24 enzyme. 
COLD SPRING HARBOR Molecular Case Studies
Treating MAD and RD patients with rapamycin and DMSO to be relatively safe for human use; however, the toxicity depends on the dosage used and the route of administration (Ali 2001; Ali and Mousa 2001; Jacob and de la Torre 2009; Budinich et al. 2013).

Rapamycin binds and modulates the kinase activities of MTOR. MTOR forms two complexes, MTORC1 and MTORC2. These complexes contain several proteins, among which raptor and rictor are recruited specifically to MTORC1 and MTORC2, respectively. It has been demonstrated that inhibition of MTOR decreases epithelial stem cell depletion and therefore the beneficial effect of rapamycin seen in animal models of progeria may relate to this effect (Burtner and Kennedy 2010). However, immunoblot analysis of cellular lysate from MADB patients treated with rapamycin did not reveal any changes in the phosphorylation of these proteins. Inactivation of the MTOR pathway could be an effect of cell culture conditions or, alternatively, it could be due to the specific location from which the dermal cells are obtained. Although we do see improvement in nuclear morphology upon rapamycin treatment, we were unable to see any significant changes in the effector(s) of rapamycin molecules as discussed above. It is also likely that fibroblasts are not the cells of choice for understanding the mechanisms by which rapamycin improves nuclear morphological abnormalities.

There are many cellular mechanisms that lead to cellular senescence, some driven by activation of CDKN2A-RB1, TP53-CDKN1A (cyclin-dependent kinase inhibitor 1A, also known as cyclin-dependent kinase interacting protein 1 [pCIP1]), nuclear DNA damage, or simply alteration in chromatin organization (Adams 2009; Kuilman et al. 2010). In this study, we found no effect of DMSO and rapamycin on the expression of CDKN2A. However, as mentioned above, this will require additional experiments to explore the synergistic effects of the two compounds tested here, although the two compounds seem to have different molecular mechanisms.

The next observation we made was the proliferative potential of the RD fibroblasts, which was similar to that of unaffected controls, as judged by the incorporation of BrdU in the DNA of proliferating cells. Because we could detect only prelamin A, even at late passages, it is intriguing to observe the role of prelamin A in cellular growth. In this study, we did not determine whether the prelamin A is farnesylated or unfarnesylated. This observation is similar to our previous report where we constitutively expressed prelamin A in HEK293 cells and found that it localized to the nuclear rim and did not alter nuclear morphology (Pan et al. 2007). Although the role of SUN (Sad1/UNC84) domain-containing proteins is not studied directly, it was reported that homologous gene deletion for SUN1 in Lmna ${ }^{-/}$(Chen et al. 2012) and Lmna 49 (Chi et al. 2012) mice resulted in increased longevity. SUN domain-containing proteins are found in the inner nuclear membrane of somatic cells and interact with the carboxyterminal KASH domain of Nesprin proteins, which forms the link between the nucleoskeleton and cytoskeleton complex. Thus, it is still unclear what is the purpose of prelamin A processing in mammalian cells despite intensive studies using various mice and their crosses harboring various Lmna mutations (Davies et al. 2011). Further studies are required to understand the increased proliferation of the fibroblasts from this RD patient expressing prelamin $A$ alone.

On 2D-DIGE, the identified proteins were mostly related to the cytoskeleton family of proteins. This was expected because fibroblasts are not highly metabolically active cells. We chose to further study whether vimentin is processed by ZMPSTE24 when expressed in heterologous cultured cells. When the double-tagged vimentin was expressed in HeLa cells, which process prelamin A to produce mature lamin A, we did observe a faster migrating band on western blots that corresponds to the predicted protein size found on the mass spectroscopy analysis of the protein spots, but we were unable to chase the smaller protein fragment. Similar effects were also seen when vimentin was expressed in the RD fibroblasts, but the processing of vimentin was very poor. A previous study observed the 
cleavage of vimentin in cultured cells (Ben-Ze'ev et al. 1986) and reported that it was cleaved by caspases-3 and -7 at Asp ${ }^{85}$ and caspase- 6 at Asp ${ }^{259}$ (Byun et al. 2001). Caspases are key molecules for apoptosis machinery, but apoptosis was not studied. Vimentin is overexpressed in several epithelial cancers (Satelli and Li 2011) and hepatocellular carcinoma ( $\mathrm{HCC}$ ), and when inhibited via small RNA interference, suppresses the invasive and migratory propensity of the tumors (Pan et al. 2012). Although vimentin has been identified as a target of ZMPSTE24 in adipose tissue obtained from Zmpste24 ${ }^{-1-}$ mice (Peinado et al. 2011) and from the skin fibroblasts from patients carrying the LMNA mutations (Magagnotti et al. 2012), it is unclear how it is cleaved. Our data fail to confirm that vimentin is a target for ZMPSTE24 endoprotease. Proteolytic cleavage of vimentin could be due to some other protease(s). A recent report now shows that Ste24, a yeast homolog of ZMPSTE24, could cleave both prenylated and nonprenylated substrates, further indicating a much broader substrate profile for Ste24 and possibly ZMPSTE24. From this perspective, our unbiased proteomic study provides additional protein substrates for further studies (Hildebrandt et al. 2016)

Patients with accelerated aging, like the ones studied here, are heterogeneous genetically and phenotypically. Our data further support this argument. Those with mutations in LMNA may benefit from one therapy and those with ZMPSTE24 mutations could respond to another drug. This is because we still do not completely understand the biological role of each of these proteins. A recent clinical trial in children with HGPS treated with FNTA inhibitor, lonafarnib, showed improved vascular stiffness, bone structure, and audiological status (Gordon et al. 2012). This idea has been further elaborated recently by Gordon et al. (2016). Our data with DMSO treatment of fibroblasts from patients carrying the ZMPSTE24 mutations suggest a different therapeutic avenue for these patients. Thus, it is likely that various progeroid syndromes (i.e., MADA, MADB, HGPS, and RD) may respond to targeted therapies specifically tailored toward mutant proteins, with their toxicities and patients in mind. This will also be a challenge for those providing personalized medicine.

\section{Conclusions}

Progeroid syndromes, rare disorders, have not attracted widespread clinical interest in developing newer drugs for therapeutic treatment of these patients. In this study, we made two significant observations. First, treatment of fibroblasts from subjects carrying the ZMPSTE24 mutations with DMSO suggests a novel therapeutic avenue for these patients. Second, our proteomic analyses of fibroblasts from these patients indicate that there are additional substrates for ZMPSTE24, which could evolve into new therapeutic targets.

\section{METHODS}

\section{Cell Culture}

Human fibroblasts and HeLa cells were grown in Dulbecco's modified Eagle medium (DMEM) supplemented with antibiotic-antimycotic and $10 \%$ fetal bovine serum. Cell cultures were maintained in a humidified incubator at $37^{\circ} \mathrm{C}$ in $5 \% \mathrm{CO}_{2}$.

\section{Preparation of Cell Lysates}

Cell lysates were prepared in RIPA buffer containing protease inhibitor cocktail and sonicated using Sonics Vibracell. The lysate was precleared by centrifugation for $20 \mathrm{~min}$ at 16,000 $\mathrm{g}$ 
COLD SPRING HARBOR Molecular Case Studies
Treating MAD and RD patients with rapamycin and DMSO

and stored at $-20^{\circ} \mathrm{C}$ for further use. Protein was assayed using Bio-Rad DC protein assay according to the manufacturer's protocol (Bio-Rad).

\section{Western Blotting}

Protein $(10-35 \mu \mathrm{g})$ was separated either on $7.5 \%$ or $10 \%$ Tris- $\mathrm{HCl}$ premade gels (Bio-Rad) and transferred onto a polyvinylidene fluoride (PVDF) membrane (Millipore) using a semidry transfer protocol (Bio-Rad). The protein blots were blocked overnight in TBS-T (Tris-Buffered Saline plus $0.2 \%$ of Tween-20) containing $10 \%$ nonfat dry milk. Primary antibodies were prepared in TBS-T containing either $1 \%$ fat-free dry milk or $5 \%$ bovine serum albumin (BSA). Lamin A/C (1:5000, sc-20681), vimentin (1:5000, sc-6260), CDKN2A (1:1000, sc-1661), total AKT (1:1000, sc-8312), pAKT (1:1000, sc-7985-R) antibodies were from Santa Cruz Biotechnology. Flag-tag (1:5000, 2044S), total MTOR (1:1000, 2972S), MTORC1 (1:1000, 2971S), MTORC2 (1:1000, 2974S), total RPS6KB1 (p70, 1:1000, 9202S), and pRPS6KB1 (Pp70, 1:1000, 9205S) were from Cell Signaling Technology. Other antibodies included V5tag (1:5000, 46-0705, Invitrogen), GAPDH (1:5000, AM4300, Ambion), and ZMPSTE24 (1:250, Abgent, www.abgent.com). Lamin A/C, vimentin, total AKT, pAKT, GAPDH, Flag, V5, and CDKN2A antibodies were incubated for $1 \mathrm{~h}$ at room temperature (RT), whereas all other antibodies were incubated overnight at $4^{\circ} \mathrm{C}$. The secondary antibodies were used at a dilution of 1:5000 at RT for $1 \mathrm{~h}$ (secondary antibodies: goat anti-rabbit IgG-HRP, donkey anti-goat IgG-HRP, and donkey anti-mouse IgG-HRP were from Santa Cruz Biotechnology). The blots were developed using chemiluminescent reagents (Immobilon Western Chemiluminescent HRP Substrate, Millipore) and exposed to X-ray films. To quantify the bands obtained via western blot analysis, an Image J software-based analysis was applied (http://rsb.info.nih.gov/ij/). The blots were scanned and the area under the curve (AUC) of the specific protein signal was corrected for the corresponding AUC for the loading control (GAPDH). Other conditions were also calculated correspondingly to allow ratio comparisons.

\section{Immunofluorescence Staining}

Immunofluorescence staining and microscopy have been described in Agarwal et al. (2008). Briefly, cells were seeded on sterile glass coverslips in a six-well plate. Cells were washed with PBS, fixed with cold methanol for 20 min, and permeabilized with $0.1 \%$ Triton X-100. Cells were blocked with blocking solution (5\% FBS plus $0.3 \%$ fatty acid-free BSA in PBS). Cells were washed with PBS and were incubated with the primary antibody Lamin A/C (dilution $1: 100, \mathrm{H}-110$ ) at $37^{\circ} \mathrm{C}$ for $1 \mathrm{~h}$ and visualized with the secondary antibody goat-antirabbit IgG-Alexa Fluor 488 (dilution 1:100, Invitrogen). Cell nuclei were stained by adding 4',6-diamidino-2-phenylindole (DAPI). Images were captured using the Zeiss Axiovert $100 \mathrm{M}$ microscope. For vimentin staining, cells were incubated with vimentin antibody (V9 clone, dilution, 1:100) and secondary antibody goat-anti mouse IgG-Alexa Fluor 568, (dilution, 1:100, Invitrogen).

To determine the effect of various drug treatments on nuclear morphology, cells were treated with several compounds as follows: $1 \%$ ethanol, 1\% dimethyl sulfoxide (DMSO), 1 $\mu \mathrm{M}$ rapamycin (Cayman Chemical) dissolved in 1\% DMSO or 1\% ethanol, $10 \mathrm{mM}$ metformin (Santa Cruz Biotechnology) dissolved in water, $200 \mu \mathrm{M} N$-acetylcysteine (NAC) (SigmaAldrich) dissolved in water, $10 \mu \mathrm{M}$ probucol (Sigma-Aldrich) dissolved in 1\% ethanol, $2 \mu \mathrm{M}$ suberoylanilide hydroxamic acid (SAHA or vorinostat) (Sigma-Aldrich) dissolved in 1\% DMSO, and $50 \mathrm{ng} / \mathrm{ml}$ insulin-like growth factor-1 (IGF1) prepared according to the manufacturer's protocol (Shenandoah Biotechnology). The compounds were replaced every other day for $14 \mathrm{~d}$. Cells were treated with farnesyl transferase inhibitor (FTI-277) and 
geranylgeranyl transferase inhibitor (GGTI-297) (EMD Biosciences) and pravastatin, zoledronic acid (Sigma-Aldrich), either separately or all together, for $48 \mathrm{~h}$.

\section{Transmission Electron Microscopy}

Cells were fixed in $2.5 \%$ glutaraldehyde in $0.1 \mathrm{M}$ sodium cacodylate buffer, embedded in $2 \%$ agarose, postfixed in buffered $1 \%$ osmium tetroxide, en bloc stained in $4 \%$ uranyl acetate, dehydrated with a graded series of ethanol, and embedded in EMbed-812 resin. Thin sections were cut on a Leica Ultracut UCT ultramicrotome and stained with $2 \%$ uranyl acetate and lead citrate. Images were acquired on a FEI Tecnai G2 Spirit electron microscope equipped with a LaB6 source and operating at $120 \mathrm{kV}$.

\section{Cellular Proliferation Assay and Effect of Various Drug Treatments}

Cellular proliferation was measured using the 5-bromo-2'-deoxyuridine (BrdU) Cell Proliferation Assay Kit as suggested by the manufacturer (Cell Signaling Technology). Human fibroblasts (3000 cells per well) from control 2 (passage 14), MAD 4700.3 (passage 11) and RD 500.3 (passage 15) were plated into 96-well plates in triplicate and were incubated for $24 \mathrm{~h}$ in a $37^{\circ} \mathrm{C}, 5 \% \mathrm{CO}_{2}$ incubator. BrdU solution was added to a final concentration of $10 \mu \mathrm{M}$ and cells were further incubated for $16 \mathrm{~h}$. At the end of the incubation, culture media was removed and cells were fixed in fixing/denaturating solution for $30 \mathrm{~min}$ at RT. The incorporation of BrdU into cellular DNA was estimated using anti-BrdU antibody $(1 \times$ detection antibody, mouse $\mathrm{mAb}$ ) for $1 \mathrm{~h}$ and incubated further with an anti-mouse IgG HRP-linked antibody (1× HRP-conjugate solution) for an additional $1 \mathrm{~h}$. HRP substrate, tetramethylbenzidine (TMB) was added to develop color. The reaction was terminated by adding the stop solution. The absorbance was read at $450 \mathrm{~nm}$ within $30 \mathrm{~min}$. For each experiment a standard curve was generated. The magnitude of absorbance was proportional to the quantity of BrdU incorporated into cells, which is a direct indication of cell proliferation. The fibroblast proliferation was also tested in the presence of the following drugs: DMSO, rapamycin, metformin, NAC, probucol, SAHA, and IGF1, prepared as described earlier, for 14 d. Compounds were replaced with the respective drugs every other day. Cells were also incubated with vehicle alone as a control.

\section{Preparation of Cells for Proteomics Analysis}

Approximately $5-10 \times 10^{6}$ cells were grown from each subject to obtain $100-300 \mu \mathrm{g}$ of protein. Cells were washed with ice-cold phosphate-buffered saline (PBS) and collected in $0.5 \mathrm{ml}$ of ice-cold PBS. The cells were pelleted by a $1 \mathrm{~min}$ spin at $100 \mathrm{~g}$, supernatant was removed, and cell pellets were quickly frozen in a dry ice-ethanol bath and kept at $-80^{\circ} \mathrm{C}$ until analysis. Two dimensional-fluorescence difference gel electrophoresis (2D-DIGE) was performed by Applied Biomics. The detailed proteomics method is provided in the Supplemental Material.

\section{Proteomics Analysis}

Gel bands were trypsinized overnight following reduction and alkylation with DTT and iodoacetamide (Sigma-Aldrich). Following solid-phase extraction cleanup with Oasis HLB plates (Waters), the resulting samples were analyzed by LC/MS/MS using an Orbitrap Elite or Q Exactive Plus mass spectrometer (Thermo Electron) coupled to an Ultimate 3000 RSLC-Nano liquid chromatography system (Dionex). Peptides were eluted with a gradient $0 \%-28 \%$ buffer B (80\% [v/v] ACN, 10\% [v/v] trifluoroethanol, and $0.08 \%$ formic acid in water) over 60 min.

Raw MS data files were converted to a peak list format and analyzed using the central proteomics facilities pipeline (CPFP), version 2.0.3 (Trudgian et al. 2010; Trudgian and Mirzaei 2012). Peptide identification was performed using the X!Tandem (Craig and Beavis 2004) 
COLD SPRING HARBOR Molecular Case Studies
Treating MAD and RD patients with rapamycin and DMSO

and open MS search algorithm (OMSSA) (Geer et al. 2004) search engines against the human protein database from Uniprot, with common contaminants and reversed decoy sequences appended (Elias and Gygi 2007). The detailed proteomics method is provided in the Supplemental Material.

\section{Generation of Human Amino-Terminal Flag-Vimentin-Carboxy-Terminal-V5-Tagged Mammalian Expression Vector}

Full-length human vimentin cDNA clone was obtained from OpenBiosytems (clone ID: LIFESEQ592293, GenBank accession number: NM_003380, www.openbiosystems.com). To generate the double-tagged vimentin, the PSPORT1-hVimentin plasmid was amplified with the following primer pair: 5'-cgggatcccgATGGATTACAAGGATGACGATGACA AGtccaccaggtccgtg-3' (Vimentin-BamHI-Flag) and 5'-cggaattccgTTATGAGTCTAGTCCT AGTAGTGGGTTTGGTATTGGTTTTCCttcaaggtcatcgtg-3' (Vimentin-EcoRI-V5). Sequences for Flag and V5 epitopes are in bold and the restriction sites BamHI and EcoRI are underlined. For efficient translation we introduced the translational initiation codon ATG before the Flag epitope and simultaneously destroyed the vimentin ATG. The vimentin open reading frame (ORF) was amplified using PCR and the product was gel purified. Both the PCR product and expression vector (pcDNA3.1, Invitrogen) were digested with BamHI and EcoRI and then ligated. Positive clones identified containing the insert were sequenced to determine PCR errors. Plasmid DNA, pcDNA3.1-Flag-hVimentin-V5, was amplified using the Maxiprep kit (QIAGEN) for cell transfection experiments.

\section{Transfection of the Cells}

HeLa cells $\left(5 \times 10^{4}\right.$ cells per well) were plated in six-well plates. Cells were transfected with pcDNA3.1-Flag-hVimentin-V5 using Lipofectamine Plus according to the manufacturer's protocol (Invitrogen). Cells were collected for western blotting $24 \mathrm{~h}$ posttransfection and probed with Flag and V5 antibodies. Approximately $5 \times 10^{4}$ primary human fibroblasts were transfected with pcDNA3.1-Flag-hVimentin-V5 expression construct using Cytofect2 according to the manufacturer's protocol (Cell Applications). DNA complex was replaced after $1 \mathrm{~h}$ of incubation with antibiotic-free growth medium and incubated further at $37^{\circ} \mathrm{C}$ in a $5 \% \mathrm{CO}_{2}$ incubator for $48 \mathrm{~h}$. Cell lysates were collected as described above for western blotting.

\section{Statistical Analysis}

Statistical analysis was performed using the Statistical Package of Social Science (SPSS, www. $\mathrm{ibm} . \mathrm{com} / \mathrm{software} / \mathrm{analytics} / \mathrm{spss} /$ ). The Mann-Whitney U-test was used to compare variables of subjects. Multiple data were compared by the Kruskal-Wallis test. Categorical variables were compared by the $\chi^{2}$ test. A $P$-value less than 0.05 was considered statistically significant.

\section{ADDITIONAL INFORMATION}

\section{Data Deposition and Access}

The raw proteomics data have been deposited in the Mass Spectrometry Interactive Virtual Environment (MassIVE) repository (https://massive.ucsd.edu/) under accession number MSV000080191 and are in ProteomeXchange (http://www. proteomexchange.org/) under accession number PXD005037. 
Competing Interest Statement The authors have declared no competing interest.

Received August 8, 2016; accepted in revised form November 1, 2016.
Treating MAD and RD patients with rapamycin and DMSO

\section{Ethics Statement}

The studies were approved by the Institutional Review Boards of Osaka University Hospital and the University of Texas Southwestern Medical Center at Dallas. Each participant or their legal guardian gave their written informed consent.

\section{Acknowledgments}

We thank Abhijit Bugde for his help in cellular imaging, Laurie Mueller for preparing samples for electron microscopy, Yoko Miyoshi for preparing patient (MAD3300) fibroblast samples, and Katie Tunison for copyediting.

\section{Author Contributions}

All experiments were conceived by A.K.A.; B.A. and S.S. performed in vitro work with advice from A.K.A.; K.O. provided MAD3300 fibroblast; C.G. performed EM studies. A.G. provided clinical samples from MAD and RD patients; A.K.A. wrote the manuscript, and all authors commented on and edited the manuscript.

\section{Funding}

This work was supported by the National Institutes of Health grant R01-DK54387 and the Southwestern Medical Foundation.

\section{REFERENCES}

Adams PD. 2009. Healing and hurting: molecular mechanisms, functions, and pathologies of cellular senescence. Mol Cell 36: 2-14.

Agarwal AK, Fryns JP, Auchus RJ, Garg A. 2003. Zinc metalloproteinase, ZMPSTE24, is mutated in mandibuloacral dysplasia. Hum Mol Genet 12: 1995-2001.

Agarwal AK, Kazachkova I, Ten S, Garg A. 2008. Severe mandibuloacral dysplasia-associated lipodystrophy and progeria in a young girl with a novel homozygous Arg527Cys LMNA mutation. J Clin Endocrinol Metab 93: 4617-4623.

Ahmad Z, Zackai E, Medne L, Garg A. 2010. Early onset mandibuloacral dysplasia due to compound heterozygous mutations in ZMPSTE24. Am J Med Genet A 152A: 2703-2710.

Ahmad Z, Phadke SR, Arch E, Glass J, Agarwal AK, Garg A. 2012. Homozygous null mutations in ZMPSTE24 in restrictive dermopathy: evidence of genetic heterogeneity. Clin Genet 81: 158-164.

Ali BH. 2001. Dimethyl sulfoxide: recent pharmacological and toxicological research. Vet Hum Toxicol 43: 228-231.

Ali BH, Mousa HM. 2001. Effect of dimethyl sulfoxide on gentamicin-induced nephrotoxicity in rats. Hum Exp Toxicol 20: 199-203.

Barrowman J, Hamblet C, Kane MS, Michaelis S. 2012a. Requirements for efficient proteolytic cleavage of prelamin A by ZMPSTE24. PLoS One 7: e32120.

Barrowman J, Wiley PA, Hudon-Miller SE, Hrycyna CA, Michaelis S. 2012b. Human ZMPSTE24 disease mutations: residual proteolytic activity correlates with disease severity. Hum Mol Genet 21: 4084-4093.

Ben-Ze'ev A, Babiss LE, Fisher PB. 1986. Cleavage of vimentin in dense cell cultures. Inhibition upon transformation by type 5 adenovirus. Exp Cell Res 166: 47-62.

Budinich CS, Tucker LB, Lowe D, Rosenberger JG, McCabe JT. 2013. Short and long-term motor and behavioral effects of diazoxide and dimethyl sulfoxide administration in the mouse after traumatic brain injury. Pharmacol Biochem Behav 108: 66-73.

Burtner CR, Kennedy BK. 2010. Progeria syndromes and ageing: what is the connection? Nat Rev Mol Cell Biol 11: 567-578.

Byun Y, Chen F, Chang R, Trivedi M, Green KJ, Cryns VL. 2001. Caspase cleavage of vimentin disrupts intermediate filaments and promotes apoptosis. Cell Death Differ 8: 443-450.

Campisi J. 2001. Cellular senescence as a tumor-suppressor mechanism. Trends Cell Biol 11: S27-S31.

Campisi J, d'Adda di Fagagna F. 2007. Cellular senescence: when bad things happen to good cells. Nat Rev Mol Cell Biol 8: 729-740. 
Cao K, Graziotto JJ, Blair CD, Mazzulli JR, Erdos MR, Krainc D, Collins FS. 2011. Rapamycin reverses cellular phenotypes and enhances mutant protein clearance in Hutchinson-Gilford progeria syndrome cells. Sci Transl Med 3: 89ra58.

Chang SY, Hudon-Miller SE, Yang SH, Jung HJ, Lee JM, Farber E, Subramanian T, Andres DA, Spielmann HP, Hrycyna CA, et al. 2012. Inhibitors of protein geranylgeranyltransferase-l lead to prelamin A accumulation in cells by inhibiting ZMPSTE24. J Lipid Res 53: 1176-1182.

Chen CY, Chi YH, Mutalif RA, Starost MF, Myers TG, Anderson SA, Stewart CL, Jeang KT. 2012. Accumulation of the inner nuclear envelope protein Sun1 is pathogenic in progeric and dystrophic laminopathies. Cell 149: 565-577.

Chetty S, Pagliuca FW, Honore C, Kweudjeu A, Rezania A, Melton DA. 2013. A simple tool to improve pluripotent stem cell differentiation. Nat Methods 10: 553-556.

Chi YH, Chen CY, Jeang KT. 2012. Reversal of laminopathies: the curious case of SUN1. Nucleus 3: 418-421.

Collas P. 1999. Sequential PKC- and Cdc2-mediated phosphorylation events elicit zebrafish nuclear envelope disassembly. J Cell Sci 112(Pt 6): 977-987.

Craig R, Beavis RC. 2004. TANDEM: matching proteins with tandem mass spectra. Bioinformatics 20: 1466-1467.

Dale BA, Holbrook KA, Witt DR, Toriello HV. 1987. Abnormal keratinization in restrictive dermopathy. Curr Probl Dermatol 17: 45-51.

Davies BS, Coffinier C, Yang SH, Barnes RH II, Jung HJ, Young SG, Fong LG. 2011. Investigating the purpose of prelamin A processing. Nucleus 2: 4-9.

Elias JE, Gygi SP. 2007. Target-decoy search strategy for increased confidence in large-scale protein identifications by mass spectrometry. Nat Methods 4: 207-214.

Fong LG, Frost D, Meta M, Qiao X, Yang SH, Coffinier C, Young SG. 2006. A protein farnesyltransferase inhibitor ameliorates disease in a mouse model of progeria. Science 311: 1621-1623.

Galant D, Gaborit B, Desgrouas C, Abdesselam I, Bernard M, Levy N, Merono F, Coirault C, Roll P, Lagarde A, et al. 2016. A heterozygous ZMPSTE24 mutation associated with severe metabolic syndrome, ectopic fat accumulation, and dilated cardiomyopathy. Cells 5: 21.

Geer LY, Markey SP, Kowalak JA, Wagner L, Xu M, Maynard DM, Yang X, Shi W, Bryant SH. 2004. Open mass spectrometry search algorithm. J Proteome Res 3: 958-964.

Gordon LB, Kleinman ME, Miller DT, Neuberg DS, Giobbie-Hurder A, Gerhard-Herman M, Smoot LB, Gordon CM, Cleveland R, Snyder BD, et al. 2012. Clinical trial of a farnesyltransferase inhibitor in children with Hutchinson-Gilford progeria syndrome. Proc Natl Acad Sci 109: 16666-16671.

Gordon LB, Kieran MW, Kleinman ME, Misteli T. 2016. The decision-making process and criteria in selecting candidate drugs for progeria clinical trials. EMBO Mol Med 8: 685-687.

Hanzen S, Vielfort K, Yang J, Roger F, Andersson V, Zamarbide-Fores S, Andersson R, Malm L, Palais G, Biteau $B$, et al. 2016. Lifespan control by redox-dependent recruitment of chaperones to misfolded proteins. Cell 166: 140-151.

Heald R, McKeon F. 1990. Mutations of phosphorylation sites in lamin A that prevent nuclear lamina disassembly in mitosis. Cell 61: 579-589.

Hildebrandt ER, Arachea BT, Wiener MC, Schmidt WK. 2016. Ste24p mediates proteolysis of both isoprenylated and non-prenylated oligopeptides. J Biol Chem 291: 14185-14198.

Holbrook KA, Dale BA, Witt DR, Hayden MR, Toriello HV. 1987. Arrested epidermal morphogenesis in three newborn infants with a fatal genetic disorder (restrictive dermopathy). J Invest Dermatol 88: $330-339$.

Jacob SW, de la Torre JC. 2009. Pharmacology of dimethyl sulfoxide in cardiac and CNS damage. Pharmacol Rep 61: 225-235.

Kubben N, Zhang W, Wang L, Voss TC, Yang J, Qu J, Liu GH, Misteli T. 2016. Repression of the antioxidant NRF2 pathway in premature aging. Cell 165: 1361-1374.

Kuilman T, Michaloglou C, Mooi WJ, Peeper DS. 2010. The essence of senescence. Genes Dev 24: 2463-2479.

Magagnotti C, Bachi A, Zerbini G, Fattore E, Fermo I, Riba M, Previtali SC, Ferrari M, Andolfo A, Benedetti S. 2012. Protein profiling reveals energy metabolism and cytoskeletal protein alterations in LMNA mutation carriers. Biochim Biophys Acta 1822: 970-979

Marino G, Ugalde AP, Fernandez AF, Osorio FG, Fueyo A, Freije JM, Lopez-Otin C. 2010. Insulin-like growth factor 1 treatment extends longevity in a mouse model of human premature aging by restoring somatotroph axis function. Proc Natl Acad Sci 107: 16268-16273.

Marks PA, Breslow R. 2007. Dimethyl sulfoxide to vorinostat: development of this histone deacetylase inhibitor as an anticancer drug. Nat Biotechnol 25: 84-90.

Merideth MA, Gordon LB, Clauss S, Sachdev V, Smith AC, Perry MB, Brewer CC, Zalewski C, Kim HJ, Solomon B, et al. 2008. Phenotype and course of Hutchinson-Gilford progeria syndrome. N Engl J Med 358: 592-604 
Michaelis S, Barrowman J. 2012. Biogenesis of the Saccharomyces cerevisiae pheromone a-factor, from yeast mating to human disease. Microbiol Mol Biol Rev 76: 626-651.

Miyoshi Y, Akagi M, Agarwal AK, Namba N, Kato-Nishimura K, Mohri I, Yamagata M, Nakajima S, Mushiake S, Shima M, et al. 2008. Severe mandibuloacral dysplasia caused by novel compound heterozygous ZMPSTE24 mutations in two Japanese siblings. Clin Genet 73: 535-544.

Navarro CL, De Sandre-Giovannoli A, Bernard R, Boccaccio I, Boyer A, Genevieve D, Hadj-Rabia S, GaudyMarqueste C, Smitt HS, Vabres P, et al. 2004. Lamin A and ZMPSTE24 (FACE-1) defects cause nuclear disorganization and identify restrictive dermopathy as a lethal neonatal laminopathy. Hum Mol Genet 13: 2493-2503.

Navarro CL, Cadinanos J, De Sandre-Giovannoli A, Bernard R, Courrier S, Boccaccio I, Boyer A, Kleijer WJ, Wagner A, Giuliano F, et al. 2005. Loss of ZMPSTE24 (FACE-1) causes autosomal recessive restrictive dermopathy and accumulation of Lamin A precursors. Hum Mol Genet 14: 1503-1513.

Navarro CL, Esteves-Vieira V, Courrier S, Boyer A, Duong Nguyen T, Huong le TT, Meinke P, Schroder W, Cormier-Daire V, Sznajer Y, et al. 2014. New ZMPSTE24 (FACE1) mutations in patients affected with restrictive dermopathy or related progeroid syndromes and mutation update. Eur J Hum Genet 22: 1002-1011.

Novelli G, Muchir A, Sangiuolo F, Helbling-Leclerc A, D'Apice MR, Massart C, Capon F, Sbraccia P, Federici M, Lauro $R$, et al. 2002. Mandibuloacral dysplasia is caused by a mutation in LMNA-encoding lamin A/C. Am J Hum Genet 71: 426-431.

Pan Y, Garg A, Agarwal AK. 2007. Mislocalization of prelamin A Tyr646Phe mutant to the nuclear pore complex in human embryonic kidney 293 cells. Biochem Biophys Res Commun 355: 78-84.

Pan TL, Wang PW, Huang CC, Yeh CT, Hu TH, Yu JS. 2012. Network analysis and proteomic identification of vimentin as a key regulator associated with invasion and metastasis in human hepatocellular carcinoma cells. J Proteomics 75: 4676-4692.

Pearce LR, Komander D, Alessi DR. 2010. The nuts and bolts of AGC protein kinases. Nat Rev Mol Cell Biol 11: 9-22.

Peinado JR, Quiros PM, Pulido MR, Marino G, Martinez-Chantar ML, Vazquez-Martinez R, Freije JM, LopezOtin C, Malagon MM. 2011. Proteomic profiling of adipose tissue from Zmpste24 ${ }^{-1-}$ mice, a model of lipodystrophy and premature aging, reveals major changes in mitochondrial function and vimentin processing. Mol Cell Proteomics 10: M111.008094.

Peter M, Nakagawa J, Doree M, Labbe JC, Nigg EA. 1990. In vitro disassembly of the nuclear lamina and M phase-specific phosphorylation of lamins by cdc2 kinase. Cell 61: 591-602.

Ramos FJ, Chen SC, Garelick MG, Dai DF, Liao CY, Schreiber KH, MacKay VL, An EH, Strong R, Ladiges WC, et al. 2012. Rapamycin reverses elevated mTORC1 signaling in lamin A/C-deficient mice, rescues cardiac and skeletal muscle function, and extends survival. Sci Transl Med 4: 144ra103.

Richards SA, Muter J, Ritchie P, Lattanzi G, Hutchison CJ. 2011. The accumulation of un-repairable DNA damage in laminopathy progeria fibroblasts is caused by ROS generation and is prevented by treatment with $\mathrm{N}$ acetyl cysteine. Hum Mol Genet 20: 3997-4004.

Sadeghi-Nejad A, Demmer L. 2007. Growth hormone therapy in progeria. J Pediatr Endocrinol Metab 20: 633-637.

Satelli A, Li S. 2011. Vimentin in cancer and its potential as a molecular target for cancer therapy. Cell Mol Life Sci 68: 3033-3046.

Thompson LJ, Fields AP. 1996. $\beta_{\|}$protein kinase $C$ is required for the $G_{2} / M$ phase transition of cell cycle. J Biol Chem 271: 15045-15053.

Trudgian DC, Mirzaei H. 2012. Cloud CPFP: a shotgun proteomics data analysis pipeline using cloud and high performance computing. J Proteome Res 11: 6282-6290.

Trudgian DC, Thomas B, McGowan SJ, Kessler BM, Salek M, Acuto O. 2010. CPFP: a central proteomics facilities pipeline. Bioinformatics 26: 1131-1132.

Varela I, Pereira S, Ugalde AP, Navarro CL, Suarez MF, Cau P, Cadinanos J, Osorio FG, Foray N, Cobo J, et al. 2008. Combined treatment with statins and aminobisphosphonates extends longevity in a mouse model of human premature aging. Nat Med 14: 767-772.

Wang Y, Lichter-Konecki U, Anyane-Yeboa K, Shaw JE, Lu JT, Ostlund C, Shin JY, Clark LN, Gundersen GG, Nagy PL, et al. 2016. A mutation abolishing the ZMPSTE24 cleavage site in prelamin A causes a progeroid disorder. J Cell Sci 129: 1975-1980.

Yang SH, Qiao X, Fong LG, Young SG. 2008. Treatment with a farnesyltransferase inhibitor improves survival in mice with a Hutchinson-Gilford progeria syndrome mutation. Biochim Biophys Acta 1781: 36-39.

Young LW, Radebaugh JF, Rubin P, Sensenbrenner JA, Fiorelli G, McKusick VA. 1971. New syndrome manifested by mandibular hypoplasia, acroosteolysis, stiff joints and cutaneous atrophy (mandibuloacral dysplasia) in two unrelated boys. Birth Defects Orig Artic Ser 7: 291-297.

Zoncu R, Efeyan A, Sabatini DM. 2011. mTOR: from growth signal integration to cancer, diabetes and ageing. Nat Rev Mol Cell Biol 12: 21-35. 


\title{
COLD SPRING HARBOR Molecular Case Studies
}

\section{Progeroid syndrome patients with ZMPSTE24 deficiency could benefit when treated with rapamycin and dimethylsulfoxide}

\author{
Baris Akinci, Shireesha Sankella, Christopher Gilpin, et al.
}

Cold Spring Harb Mol Case Stud 2017, 3: a001339 originally published online November 2, 2016 Access the most recent version at doi: $10.1101 / \mathrm{mcs}$.a001339
Supplementary http://molecularcasestudies.cshlp.org/content/suppl/2016/11/02/mcs.a001339.D Material C1
References This article cites 64 articles, 14 of which can be accessed free at: http://molecularcasestudies.cshlp.org/content/3/1/a001339.full.html\#ref-list-1
License This article is distributed under the terms of the Creative Commons Attribution-NonCommercial License, which permits reuse and redistribution, except for commercial purposes, provided that the original author and source are credited.
Email Alerting Receive free email alerts when new articles cite this article - sign up in the box at the Service top right corner of the article or click here.

